\title{
Ojos que no ven, opinión que no cuestiona observar a los medios, para alertar a sus públicos'
}

\author{
JULIANA CASTELLANOS DÍAZ \\ Politécnico Grancolombiano \\ jcastell@poligran.edu.co
}

\begin{abstract}
Comunicadora Social-Periodista de la Universidad de Manizales y Magíster en Comunicación de la Pontificia Universidad Javeriana. Se ha desempeñado como catedrática, profesora de tiempo completo y en la actualidad es docente investigadora del Departamento Académico de Comunicación del Politécnico Grancolombiano. Atenta observadora del desarrollo de los observatorios de medios en las facultades de comunicación y periodismo latinoamericanas, ha concentrado su interés en estudiar y analizar las realidades construidas a partir de la acción mediática en la sociedad.
\end{abstract}

\section{Resumen}

El auge de los observatorios de medios en las facultades de comunicación social y periodismo en Colombia en los últimos dos años lleva, en primer lugar, a reflexionar sobre la relación que se teje entre las definiciones que reconocidos autores y coordinadores de observatorios plantean sobre el concepto y la experiencia, que en el país se construye a partir de 1999 cuando se instaura el primer observatorio. En segundo lugar, invita a analizar las causas del aumento de los observatorios, los objetivos sobre los que se institucionalizan, y las fortalezas y debilidades que los caracterizan.

\section{Palabras Claves}

Observatorios de medios, facultades de comunicación social y periodismo, investigación mediática, veeduría ciudadana, defensoría del lector y el televidente, medios regionales, medios nacionales.

\section{Abstract}

The rise of media observatories in the Faculties of Social Communication and Journalism in Colombia in the last two years, leads, first, to reflect on the relationship between the definitions weaves known authors and coordinators of observatories raised on the concept and experience in the country was built from 1999 when establishing the first observatory. Second, it encourages you to discuss the causes of the increase of the observatories, the goals that are institutionalized, and the strengths and weaknesses that characterize them.

\section{Key words}

Media observatories, schools of Social

Communication and Journalism, media research, public oversight, advocacy of the reader and the viewer, regional media, national media.

\section{Fecha de recepción: 14 de septiembre de 2010} Fecha de aprobación: 12 de octubre de 2010

\section{Introducción}

Como los prisioneros del mito de la caverna de Platón, las sociedades modernas están cautivas en una burbuja de significados construidos por los medios. Cuando miran a través de ellos descubren sombras que algunas veces se tornan claras y otras tantas confusas; pero la prisa a la que los sujetos se ven sometidos, no da tregua para reflexionar sobre esa maraña de imágenes que, aunque lejanas y cuestionamientos en un intento por sobrevivir al orden allí establecido.

No obstante, hay otros personajes en ese lugar que después de observar con detenimiento descubren que existe otro lado, fuera de la caverna, en el que permanece encendida una hoguera, y tras ella un cúmulo de titiriteros manipulando figuras para proyectar otras: las planeadas, las que obedecen a una estrategia. Llegar hasta la hoguera es complejo, sin embargo, queda la opción de agudizar la observación para, al menos, alertar a las personas de los entramados simbólicos con los que muchas veces quieren cegarlos.

En Colombia, el lugar desde el que se observa con cuidado a los medios se concentra en las facultades de comunicación social y periodismo, por medio de los denominados observatorios de medios, pero ¿cómo pueden explicarse?

La pregunta es pertinente en tanto que hay un afán vertiginoso en la academia por consolidar observatorios, no obstante la sociedad carece de reflexiones teóricas que constituyan un marco conceptual claro mediante

1 El proyecto de investigación del cual es producto este documento, ha sido financiado por la Fundación Universitaria

Politécnico Grancolombiano, mediante el contrato de investigación (No. 2010FCCACECTC28), del 14 de diciembre de 2009. 
el cual puedan comprender, con más exactitud, lo que esas figuras representan. En consecuencia, el siguiente texto hace una pesquisa por las definiciones que algunos reconocidos estudiosos hacen del concepto, así como las que proponen los directores de distintos observatorios universitarios a partir de su experiencia.

Susana Herrera manifiesta que "los observatorios son instancias de supervisión mediática que vigilan y controlan la actividad de los medios" (2005, p. 3). En principio podría pensarse que los observatorios se aproximan a la supervisión mediante investigaciones en las que explican el tratamiento informativo que los periodistas dan a determinados temas. Pero, en concordancia con la definición expuesta, la supervisión y vigilancia implican no solo el seguimiento y análisis, sino la posibilidad de intervenir en el hacer del medio, lo que la mayoría de las veces no ocurre, porque los observatorios carecen de influencia en el desarrollo de las actividades de los emisores, debido a que en Colombia no se ha establecido un conducto de comunicación mediante el cual los medios y la academia consoliden diálogos sobre el quehacer de ambas partes.

Es por ello que los once coordinadores de observatorios entrevistados rechazan la idea de asumir el observatorio como un quinto poder que pueda yuxtaponerse a los medios. Todos afirman que el trabajo que se realiza tiene un carácter pedagógico, no fiscalizador, pues contribuye a fortalecer el ejercicio de la academia, más que a intervenir en la forma y el contenido de los medios de masas. Ahora bien, no se puede desconocer el esfuerzo que algunos coordinadores de observatorios hacen para acercar los resultados de sus estudios a directores, periodistas y editores, así como a la ciudadanía.

Las siguientes dos respuestas permiten aproximarse a la posición de los coordinadores de observatorios frente al tema en cuestión.

Los observatorios son un espacio desde la academia o la sociedad civil, pero nunca serán unn poder; incluso el 11 amado cuarto poder cada vez se ve más resquebrajado con la aparición y desarrollos de proyectos emergentes o alternativos de medios en formato digitall, asegura Pedro Pablo Aguilera, coordinador del observatorio de medios de la Universidad Santiago de Cali.
No hay poder, el poder es la capacidad de actuar sobre el pensamiento social. A La sociedad colombiana no le interesan los resultados de los observatorios, no hay conciencia ciudadana de revisair los medios de comunicación, manifiesta Alejandro Rodríguez, coordinador del observatorio de medios de la Universidad Centrall.

Es evidente que en Colombia se desdibuja el pensamiento de Ignacio Ramonet, quien propuso, en el Foro Social Mundial de Porto Alegre de 2002, consolidar por medio de los observatorios un poder superior al mediático, que sería nombrado el Quinto Poder.

Más allá del poder, Sara Brombart y Ernesto Lamas manifiestan que los observatorios son "experiencias de participación social, de ejercicio de los derechos a la comunicación, la información y la libertad de expresión" (2003). Los observatorios universitarios son, en su mayoría, una experiencia en la que la participación social se reduce al número de personas que trabajan directamente con el proyecto. De manera que no se trata de una experiencia comunitaria, con excepción de algunos proyectos que exigen trabajar con receptores; pero incluso en estos casos los receptores son un objeto de estudio a merced de los investigadores, en ocasionales encuentros de carácter metodológico (talleres o focus group).

Sin embargo, no se desconoce que los otros aspectos que mencionan Brombart y Lamas (2003), como el derecho a la comunicación y la libertad de expresión, son elementos fundacionales de los observatorios. En Colombia estas instancias tienen su razón de ser en el respaldo a estos derechos a partir de análisis y llamados de atención a los mass media, aunque, esos llamados no tienen consecuencias notorias.

Rogério Christofoletti (2006) expone que la observación de medios es una experiencia, que puede ser entendida como iniciativa y proyecto, que va desde un observatorio de medios hasta blogs y sites personales en la web. Esta explicación valida la vigilancia de los medios hecha por cualquier sujeto. El único requerimiento es contar con un escenario digital que visibilice el análisis, pero ¿quién legitima esos estudios espontáneos? El riesgo de los documentos de la web es que pueden ser producto de la inspiración más que de un proceso investigativo serio. Por tanto es contraproducente, incluso irresponsable, confundir un observatorio de medios con la opinión sobre los medios. 
Jorge Iván Bonilla y Omar Rincón plantean que un observatorio de medios es "una estrategia de observación y análisis para hacer seguimiento a los medios masivos" (en Zuluaga, 2007, p.35). La explicación tiene la virtud de no limitar la experiencia a la difícil y controvertida tarea de vigilar y controlar; tampoco la reducen a las opiniones de algunos sujetos sobre los mensajes mediáticos. Por el contrario, ubican a los observatorios en el plano de la investigación al hacer referencia a las estrategias de observación, esto es metodologías para el seguimiento de medios de comunicación.

Esta definición se aproxima al banco de experiencias que, desde hace una década, se suman en las facultades de Comunicación Social de Colombia, en donde la investigación mediológica se viene desarrollando en el marco de observatorios de medios, tras un afán de la academia por seguir cuidadosamente, con metodologías cualitativas y cuantitativas, los contenidos de los medios de comunicación nacionales y regionales. Los directores de observatorios justifican este ejercicio desde tres ángulos conexos: los medios convertidos en empresas de los grandes grupos económicos, el conflicto armado y el uso de los medios como escenario de lucha de intereses de los actores del conflicto. Aunque no debe desconocerse otras causas como las actuales producciones de televisión sobre el tema del narcotráfico, el interés por los nuevos medios y sus formas de construcción de información, y la representación mediática de problemáticas específicas locales.

Dos definiciones más se acercan a la forma cómo en Colombia se comprende y se practica la observación de medios. Erik Torrico (2009) plantea que los observatorios son espacios de supervisión del desempeño mediático, en especial del campo noticioso y Germán Ortiz y Daniel Fernando López (2002, p.6) asumen que se trata de un laboratorio de experimentación para analizar medios masivos de comunicación y sus efectos en la sociedad.

Ambas explicaciones describen los dos escenarios más comunes en los que los observatorios de medios surgen en las universidades del país. El primero es la consolidación de una instancia, o espacio, para observar los medios desde unas categorías específicas que responden a los intereses de la facultad, para lo cual se trazan líneas de investigación; se trata, entonces, del montaje, en primer lugar, del observatorio y, a posteriori, de la puesta en marcha de investigaciones concretas. El segundo escenario parte de un cúmulo de investigaciones sobre los medios de masas que, de manera voluntaria o planeada, producen los académicos, lo que en algún momento deciden enmarcar dentro de un observatorio.

A continuación se presenta un cuadro en el que se visibilizan las respuestas que algunos de los directores de observatorios de medios de las facultades de Comunicación Social de Colombia dan a la pregunta: ¿Cómo definir desde la experiencia un observatorio de medios? Las respuestas demuestran la carencia de una teoría clara sobre el concepto en discusión, lo que lleva a que las definiciones sean, en algunos casos, dispersas. Sin embargo, en la esencia de cada respuesta es clara la concepción de los observatorios como escenarios de investigación mediática (cuadro 1).

Cuadro 1. ¿Cómo definir desde la experiencia un observatorio de medios?

\begin{tabular}{|c|c|}
\hline Nombre del observatorio & Respuesta de los directores \\
\hline $\begin{array}{l}\text { Observatorio de Medios y } \\
\text { de Opinión } \\
\text { Universidad de Manizales } \\
\text { Coordinador } \\
\text { Julián Burgos }\end{array}$ & $\begin{array}{l}\text { Básicamente un observatorio } \\
\text { es una unidad que investiga } \\
\text { los medios para incidir en ellos } \\
\text { y en sus comunidades de in- } \\
\text { fluencia. Un observatorio tiene, } \\
\text { por naturaleza, una perspec- } \\
\text { tiva política, tanto como una } \\
\text { académica. En esa medida es } \\
\text { como orientar la proyección de } \\
\text { la universidad desde lo que la } \\
\text { investigación genera. }\end{array}$ \\
\hline $\begin{array}{l}\text { Observatorio de Medios } \\
\text { Facultad de Comunicación } \\
\text { Universidad de la Sabana } \\
\text { Coordinador } \\
\text { Juan Camilo Hernández. }\end{array}$ & $\begin{array}{l}\text { Es valioso, no solo por la gente } \\
\text { sino por el crecimiento que } \\
\text { se da por el intercambio de } \\
\text { opinión, ya que en Colombia la } \\
\text { investigación es poco valorada. } \\
\text { Es una herramienta de segui- } \\
\text { miento del "Acuerdo por la } \\
\text { discreción" con los periodistas } \\
\text { (tomado de la web del obser- } \\
\text { vatorio). }\end{array}$ \\
\hline $\begin{array}{l}\text { Observatorio de Medios } \\
\text { Universidad Santiago de } \\
\text { Cali. } \\
\text { Coordinador } \\
\text { Pedro Pablo Aguilera }\end{array}$ & $\begin{array}{l}\text { Es compleja, porque exige } \\
\text { estudio y debate conceptual, } \\
\text { construir consensos y aceptar } \\
\text { muchas veces la mirada de } \\
\text { otros. El trabajo en equipo es } \\
\text { apasionante, fructifero, pero } \\
\text { hay veces que da lugar a } \\
\text { debates muy álgidos. Permite } \\
\text { acercar la teoría a la práctica } \\
\text { docente y los estudiantes a las } \\
\text { dinámicas reales. }\end{array}$ \\
\hline $\begin{array}{l}\text { Observatorio de Medios } \\
\text { Universidad Javeriana }\end{array}$ & $\begin{array}{l}\text { Es una metodología que permi- } \\
\text { te el análisis de medios. }\end{array}$ \\
\hline
\end{tabular}




\begin{tabular}{|c|c|}
\hline Nombre del observatorio & Respuesta de los directores \\
\hline $\begin{array}{l}\text { Observatorio de Medios y } \\
\text { Opinión Pública } \\
\text { Universidad del Norte } \\
\text { Coordinadora } \\
\text { Marta Milena Barrios. }\end{array}$ & $\begin{array}{l}\text { Son experiencias ciudadanas } \\
\text { de reflexión que parten de } \\
\text { objetivos temáticos y meto- } \\
\text { dologías de trabajo distintas, } \\
\text { que responden a necesidades } \\
\text { sentidas de la sociedad o co- } \\
\text { munidad, además de entender } \\
\text { a los medios de comunicación } \\
\text { como producto de la cultura y } \\
\text { reflejo de la misma. }\end{array}$ \\
\hline $\begin{array}{l}\text { Observatorio de Medios de } \\
\text { la Universidad de Medellín. } \\
\text { Coordinador } \\
\text { Andrés Felipe Giraldo } \\
\text { Dávila. }\end{array}$ & $\begin{array}{l}\text { Como un grupo de investiga- } \\
\text { ción en Colciencias, como un } \\
\text { proyecto de extensión univer- } \\
\text { sitario o como una fundación } \\
\text { con recursos diversos. }\end{array}$ \\
\hline $\begin{array}{l}\text { Observatorio de Medios de } \\
\text { la Universidad Central. } \\
\text { Coordinador } \\
\text { Alejandro Rodríguez. }\end{array}$ & $\begin{array}{l}\text { Como un proceso que ayuda a } \\
\text { la modificación de asignaturas. }\end{array}$ \\
\hline $\begin{array}{l}\text { Observatorio Regional de } \\
\text { Medios de Informa } \\
\text { ción y Comunicación del } \\
\text { Oriente } \\
\text { (Ormic) } \\
\text { Universidad Autónoma de } \\
\text { Bucaramanga } \\
\text { Coordinador } \\
\text { Manfry Gómez Ditta }\end{array}$ & $\begin{array}{l}\text { Es un espacio de carácter in- } \\
\text { terinstitucional e interdiscipli- } \\
\text { nario de análisis, seguimiento } \\
\text { y socialización de las activida- } \\
\text { des, procesos, problemáticas } \\
\text { y perspectivas, que desde } \\
\text { los medios de información } \\
\text { y comunicación existen en } \\
\text { el oriente colombiano. Tiene } \\
\text { como propósito generar en } \\
\text { forma permanente reflexio- } \\
\text { nes acerca del trabajo de los } \\
\text { comunicadores sociales, para } \\
\text { dinamizar otras propuestas } \\
\text { de mejoramiento en la calidad } \\
\text { de la información existente. } \\
\text { Es interinstitucional porque } \\
\text { integra iniciativas, no solo de } \\
\text { carácter académico sino tam- } \\
\text { bién experiencias de medios y } \\
\text { organizaciones gremiales. }\end{array}$ \\
\hline $\begin{array}{l}\text { Observatorio de Medios } \\
\text { Digitales } \\
\text { Corporación Universitaria } \\
\text { Lasallista } \\
\text { Caldas, Antioquia } \\
\text { Coordinador } \\
\text { Juan Luis Ângel Carreño }\end{array}$ & $\begin{array}{l}\text { En general compartimos la } \\
\text { idea de que el observatorio es } \\
\text { una invitación para compren- } \\
\text { der la acción de los medios, el } \\
\text { firmamento de la información, } \\
\text { la transformación de los me- } \\
\text { dios para establecer puntos de } \\
\text { encuentro entre lo académico, } \\
\text { las organizaciones y el público. }\end{array}$ \\
\hline
\end{tabular}

\section{¿Observatorios de medios, veedurías ciudadanas o defensorías de lectores y televidentes?}

Es común encontrar en algunos documentos sobre observatorios de medios el uso de dos conceptos como sinónimos de este: veedurías ciudadanas y defensoría del lector o del televidente. Es pertinente, entonces, acercarse a los significados para comprender los límites y las intersecciones entre esta triada de nombres que pueden llevar a la confusión.

Las veedurías se comprenden, en Colombia, como

un mecanismo democrático de representación que le permite a los ciudadanos o a las diferentes organizaciones comunitarias, ejercer vigillancia sobre la gestión pública, respecto a las autoridades administrativas, políticas, judiciales, electorales, legislativas y órganos de control, así como de las entidades públicas o privadas, organizaciones no gubernamentales de carácter nacional o internacional que operen en ell país, encargadlas de la ejecución de un programa, proyecto, contrato o de la prestación de un servicio público" (Ley 850 de 2003 y el Acuerdo 142 de 2005 por la cual se reglamentan las veedurías ciudadanas)..

En principio, los observatorios pueden ser reconocidos como veedurías en tanto que supervisan la información mediática que, entendida desde el derecho a la información, se trata de una cuestión pública. Sin embargo, una veeduría es reconocida como tal mediante un documento o acta de constitución legal, que se inscribe ante personerías municipales o cámaras de comercio. Los observatorios, al menos los consolidados desde universidades, no se registran en las nombradas instituciones bajo la figura en cuestión. En suma, no podría desconocerse que una veeduría puede encaminarse al seguimiento de la información mediática, sin embargo, vigilar no significa investigar, que es de algún modo el sentido que en Colombia se le ha dado a los observatorios.

Respecto al defensor del lector, se debe anotar que en la actualidad es muy poco lo que queda de ese personaje, aunque sobrevive con fuerza el denominado defensor del televidente exigido por la Comisión Nacional de Televisión a los canales privados en el artículo 11 de la Ley 335 de 1996, y a los canales públicos y regionales en la resolución 1.o de 2007. La Comisión explica que el defensor es necesario

a fin de que la audiencia conozca el trámite y sollución a las quejas y demás aspectos relacionados con los conte- 
nidos de la programación y de la publicidlad, gestionados por el Canal (Acuerdo 1 de 2007 Comisión Nacional de Televisión).

Lo anterior deja claro que el defensor del televidente, incluso del lector, es más un mediador entre la empresa y el usuario que, en términos reales, suele defender más a la empresa para la que trabaja que al consumidor. Por el contrario, los observatorios son instancias de estudio científico del proceso de comunicación de masas, más que receptoras de reclamos de los televidentes y lectores. Lo que sí puede ocurrir es que de este cúmulo de quejas surjan interrogantes que den lugar a una investigación.

Lo anterior confirma que no es acertado hablar de observatorios de medios como si de veedurías o defensores del televidente se tratara. Es necesario asumir que existen límites conceptuales, procedimentales y pragmáticos. Por tanto es tangible la necesidad de intentar una definición, abierta al debate, sobre los observatorios de medios, en la que no se desconozca la experiencia adquirida en ese campo en la academia colombiana:

Un observatorio de medios es un bastión de la investigación mediática (físico o virtual), que desde las facultades de Comunicación Social y Periodismo, y en cabeza de docentes interesados en el acercamiento entre la teoría y la práctica, se preocupa por: (a) La calidad, veracidad, imparcialidad y pertinencia de la información mediática de orden local, comunitaria, regional, nacional, internacional. (b) Las estéticas mediáticas de dicha información y sus transformaciones en el tiempo. (c) Las rutinas de producción de información vigentes y los sujetos emisores que las vivencian. (d) La construcción de sentido que hacen los receptores y usuarios a partir de la información mediática.

\section{Observando la experiencia}

De la reflexión teórica es importante pasar a la práctica, en un intento por relatar al lector el lugar que vienen a ocupar desde 1999 los observatorios de medios en Colombia, cuando se consolida el Observatorio de Medios y Opinión Pública de la Universidad de Manizales y, un año después, el Observatorio de Medios de la Universidad de la Sabana. Al entrar el nuevo siglo, otras facultades de Comunicación Social y Periodismo han sentido la necesidad de desarrollar prácticas semejantes, al punto que en la actualidad el país cuenta con once observatorios constituidos y dieciocho proyectos encaminados a serlo en el corto plazo.
El crecimiento de los observatorios en la última década es proporcional al apoyo del que estas figuras gozan, cada vez más, en las distintas universidades, donde estos se han convertido en bastiones de investigación mediática y, en consecuencia, en herramienta pedagógica que sirve para el desarrollo de prácticas analíticas de las rutinas periodísticas, de los textos que desde allí se producen, de las realidades que estos consolidan y de los efectos sociales que lo anterior produce.

A continuación se citan tres experiencias que permiten acercarse a las motivaciones que dan lugar a la creación de observatorios: Julián Burgos, director del Observatorio de Medios de la Universidad de Manizales, relata que el proyecto que dirige

se creó como un espacio para la identificación, sistematización, clasificación e interpretación de fenómenos relacionados con los emisores de los medios de comunicación de la región y sus audiencias.

Mari Luz Vallejo, una de las coordinadoras del Observatorio de Medios de la Universidad Javeriana, cuenta que

todo comenzó con un proyecto de investigación titulado ¿Qué es noticia? Agendas, ciudadanos, periodistas, que se publicó a finales de 2004. Fúe un trabajo enriquecedor porque ahí se construyó la matriz de análisis que se ha seguido manejando, con las adaptaciones que cada tema exige.

Juan Camilo Hernández, integrante del grupo del Observatorio de Medios de la Universidad de la Sabana, recuerda:

En 2000 comenzamos a investigar por qué la libertad de prensa era coartada, y analizamos el contenido de medios audiovisuales. Los hechos que nos motivaron fueron la etapa negra del periodismo (1998-1999), el ingreso de la televisión privadla (emisión en vivo), y el terremoto del Eje Cafetero en 1998 porque los medios se aprovecharon de eso para hacer una presentación amarillista

Las respuestas evidencian los ejes problemáticos sobre los que se gestan un gran número de observatorios universitarios: los sujetos emisores, las rutinas periodísticas, las agendas mediáticas, las formas de construcción de la información en momentos coyunturales y las consecuencias de lo mencionado en la opinión pública, todo esto en el plano regional y nacional.

El cuadro 2 presenta los once observatorios de medios reconocidos en Colombia, el orden en el que surgieron y los objetivos que los fundamentan: 


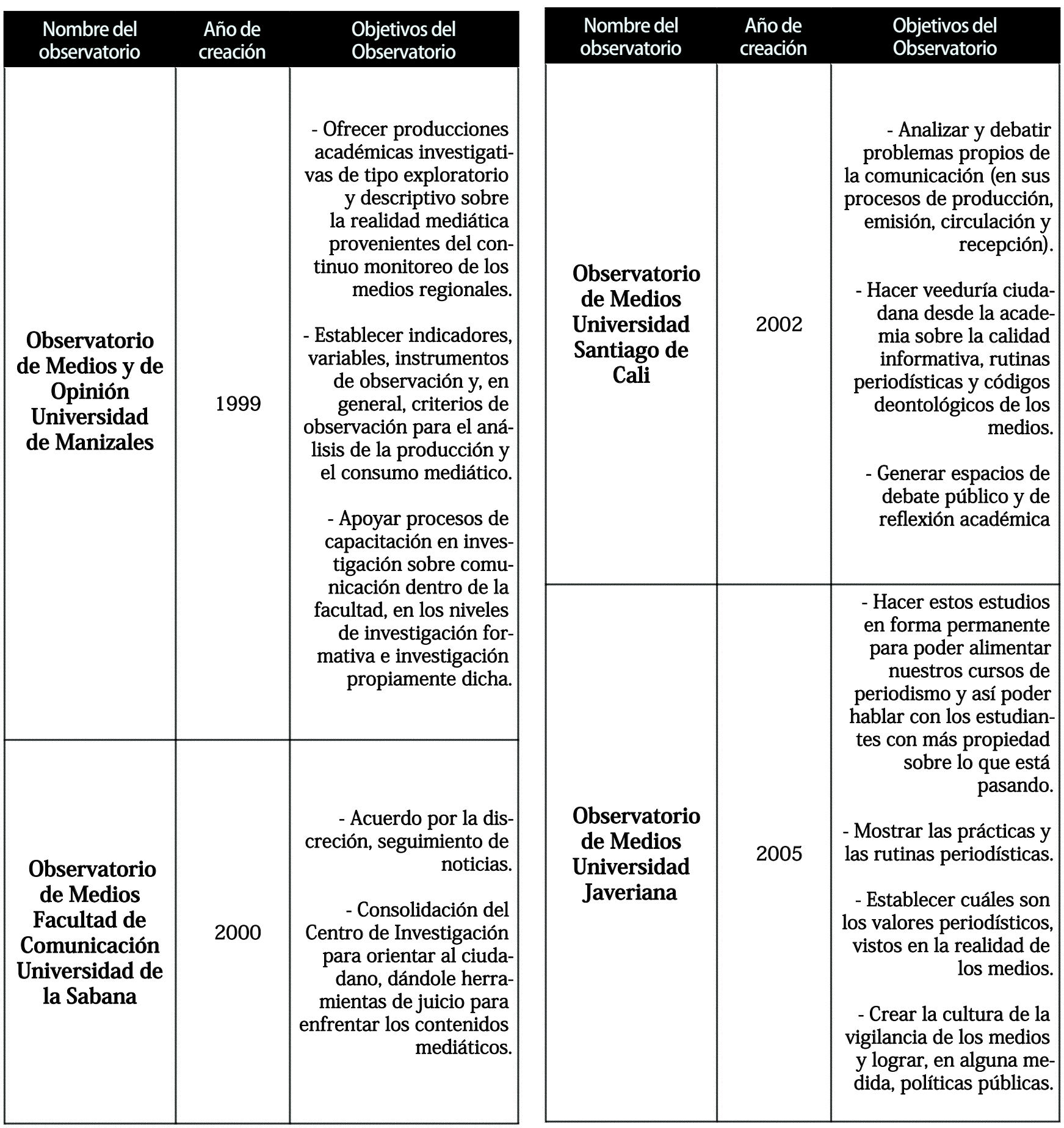




\begin{tabular}{|c|c|c|}
\hline $\begin{array}{l}\text { Nombre del } \\
\text { observatorio }\end{array}$ & $\begin{array}{l}\text { Año de } \\
\text { creación }\end{array}$ & $\begin{array}{l}\text { Objetivos del } \\
\text { Observatorio }\end{array}$ \\
\hline $\begin{array}{l}\text { Observatorio } \\
\text { de Medios y } \\
\text { Opinión Públi- } \\
\text { ca Universidad } \\
\text { del Norte }\end{array}$ & 2006 & $\begin{array}{r}\text { - Analizar la informa- } \\
\text { ción pública que produ- } \\
\text { cen los medios de comu- } \\
\text { nicación para propender } \\
\text { por la excelencia en el } \\
\text { ejercicio profesional, } \\
\text { que beneficie la toma } \\
\text { de decisiones de los } \\
\text { ciudadanos y fortalezca } \\
\text { la democracia. }\end{array}$ \\
\hline $\begin{array}{c}\text { Observatorio } \\
\text { de Medios } \\
\text { Universidad de } \\
\text { Medellín. }\end{array}$ & 2007 & $\begin{array}{r}\text { - Analizar la informa- } \\
\text { ción contenida en los } \\
\text { medios de comunica- } \\
\text { ción. }\end{array}$ \\
\hline $\begin{array}{l}\text { Observatorio } \\
\text { de Medios } \\
\text { Universidad } \\
\text { Central. }\end{array}$ & 2007 & $\begin{array}{l}\text { - Balance sobre calidad } \\
\text { de información en pren- } \\
\text { sa impresa y digital. } \\
\text { - Hacer un seguimiento } \\
\text { a los candidatos y sus } \\
\text { programas. }\end{array}$ \\
\hline $\begin{array}{l}\text { Observatorio } \\
\text { Regional de } \\
\text { Medios de } \\
\text { Información y } \\
\text { Comunicación } \\
\text { del Oriente } \\
\text { (Ormic) } \\
\text { Universidad } \\
\text { Autónoma de } \\
\text { Bucaramanga. }\end{array}$ & 2009 & $\begin{array}{l}\text { - Identificar las imá- } \\
\text { genes de región que } \\
\text { circulan en los medios } \\
\text { y determinar las formas } \\
\text { como las organizaciones } \\
\text { empresariales y sociales } \\
\text { de la comunicación del } \\
\text { oriente colombiano con- } \\
\text { tribuyen a la construc- } \\
\text { ción del vínculo social. }\end{array}$ \\
\hline
\end{tabular}

\begin{tabular}{|c|c|c|}
\hline $\begin{array}{l}\text { Nombre del } \\
\text { observatorio }\end{array}$ & $\begin{array}{l}\text { Año de } \\
\text { creación }\end{array}$ & $\begin{array}{l}\text { Objetivos del } \\
\text { Observatorio }\end{array}$ \\
\hline $\begin{array}{c}\text { Observatorio } \\
\text { de Medios Digi- } \\
\text { tales } \\
\text { Corporación } \\
\text { Universitaria } \\
\text { Lasallista } \\
\text { Caldas, Antio- } \\
\text { quia }\end{array}$ & 2009 & $\begin{array}{r}\text { - Analizar los cam- } \\
\text { bios comunicativos y de } \\
\text { contenido de los nuevos } \\
\text { medios digitales. } \\
\text { - Investigar los fenómenos } \\
\text { y la estructura de la co- } \\
\text { municación en los nuevos } \\
\text { medios tecnológicos. } \\
\text { - Aplicar las mejores prác- } \\
\text { ticas comunicativas de las } \\
\text { TIC en los diversos sec- } \\
\text { tores de la sociedad como } \\
\text { los espacios académico, } \\
\text { privado, cultural y social. } \\
\text { - Investigar las herramien- } \\
\text { tas periodísticas más efec- } \\
\text { tivas en el mundo de los } \\
\text { nuevos medios digitales. }\end{array}$ \\
\hline $\begin{array}{l}\text { Observatorio } \\
\text { de Medios } \\
\text { Universidad } \\
\text { Nacional de } \\
\text { Colombia }\end{array}$ & 2010 & $\begin{array}{r}\text { - Observar en forma } \\
\text { sistemática y detenida el } \\
\text { contenido de los medios y } \\
\text { de sus formas de operar; } \\
\text { incidir en sus lugares de } \\
\text { emisión con la divul- } \\
\text { gación de los resultados de } \\
\text { nuestros ejercicios y con la } \\
\text { invitación a la reflexión y } \\
\text { el debate. }\end{array}$ \\
\hline
\end{tabular}

Fuente : Castellanos Díaz Juliana (2010, p. 14).

El cuadro 2 permite entender que los observatorios de las ciudades distintas a Bogotá se concentran en estudios de recepción local, así como en el análisis de los medios regionales y las formas en que estos representan las realidades socioculturales, políticas y económicas de sus contextos inmediatos; además, incluyen en sus objetos de investigación el contenido de los medios nacionales. Por el contrario, las universidades del centro del país se inclinan, por lo general en la observación de los medios nacionales y dejan de lado el estudio de lo regional.

La anterior caracterización conduce a la indagación de las fortalezas y debilidades de los observatorios de medios de las facultades de Comunicación Social del país. 
A partir de las entrevistas con los directores de estos proyectos se pueden deducir los siguientes aspectos:

\section{Fortalezas}

- $\quad$ El uso de metodologías en las que combinan lo cualitativo y lo cuantitativo.

- La proyección social y pedagógica que intentan desde las investigaciones.

- La constitución de grupos de investigación categorizados ante Colciencias.

- El esfuerzo que hacen por visibilizar los resultados de sus estudios en revistas indexadas de carácter nacional e internacional, así como en espacios mediáticos.

- El afán de estudiar la comunicación de masas sin caer en dimensiones mediacentristas, desde múltiples esferas: las industrias culturales, las rutinas de producción de mensajes, los mensajes, los emisores y las audiencias.

\section{Debilidades}

- El escaso número de docentes que trabajan en cada uno de los observatorios.

- La carencia de redes de observatorios en Colombia, consecuencia del trabajo aislado que hacen las universidades.

- La falta de comunicación entre los observatorios, la ciudadanía y los medios que se estudian.

- La escasa repercusión que tienen las investigaciones de los observatorios en el quehacer periodístico.

- La carencia de un marco teórico sólido sobre el concepto observatorio de medios.

Además de los once observatorios de medios ya constituidos, surge la pregunta por los dieciocho proyectos en perspectiva. ¿Qué motiva a las facultades de Comunicación Social y Periodismo del país a constituir, en el último año, observatorios de medios? En un artículo anterior, publicado en la revista mexicana Razón y Palabra, señalaba que hay tres factores motivacionales sobre los que se tejen estos nuevos proyectos:

El primero es el afán que sienten las faculltades de comunicación por consolidar métodos para monitorear los textos y los discursos mediáticos nacionales y regionales, y la ilusión de poder intervenir en ellos desde la creación de políticas públicas o, al menos, la concientización de quienes forjan los contenidos. Ell segundo son las coyunturas de orden político y militar que ha vivido el país desde el primer mandato del presidente Âlvaro Uribe all interior y exterior de Colombia, así como el fenómeno mediático en el que se convirtió el ex presidente. Ell tercero se da desde 2009 cuando Ascuin invita a las instituciones de educación superior a consolidar observatorios de televisión, en el marco del proyecto Red de observatorios de televisión que pone en marcha la Comisión Nacional de Televisión (Castellanos, 2010, p.19).

Carla Ricci, coordinadora de la Red de observatorios de televisión desde Ascun señala:

Lo que nosotros hacemos es propiciar la creación de observatorios, en general de medios, pero con un fuerte énfasis en televisión. La televisión es el medio de comunicación de mayor impacto, porque es el que más consumen los colombianos. Desde Ascuin no desconocemos el aporte de otros medios como la radio o la prensa, pero sabemos que la televisión es la caja mágica que nos permite la transfoma. ción de la sociedad.

La red también está conformada por observatorios con amplia experiencia; experiencias que son compartidas con los docentes e investigadores que hasta ahora planean sus observatorios.

En forma independiente, otras facultades de Comunicación están en la tarea de consolidar observatorios de medios digitales, con el fin de aproximarse a estos nuevos objetos de estudio tan poco explorados en América Latina. La Universidad Autónoma del Caribe y el Politécnico Grancolombiano son ejemplo de ello. En la primera, el interés se centra en la prensa digital colombiana; en el segundo, la investigación gira en torno a la prensa digital de los países fronterizos.

Es de notar que la creación de observatorios se produce en un momento histórico en el que la gente cada vez más se sumerge en una vida fabricada por los medios; no en vano, muchas personas tienen hoy las mismas aspiraciones (una casa, dos carros, muchos viajes, bastante ropa). Por ello el trabajo que se hace desde la academia es fundamental, en tanto que sobre la tarea de observar a los medios está la de alertar a sus públicos, motivar la crítica, alentar el cuestionamiento y forjar una opinión pública más consciente de los contenidos que recibe.

\section{Bibliográfia}

1. Brombart, S.; \& Lamas, E. (2003). Introducción en: veedurías y observatorios. Participación social en los medios de comunicación. Buenos Aires: La Tribu.

2. Christofoletti, R. (2006). Un observatorio brasileño. Revista Latinoamericana de Comunicación Chasqui (95).

3. Castellanos Díaz, Juliana (2010). Los observatorios de medios: bastiones de la investigación mediática. Revista Razón y Palabra (73). 
4. Diario Oficial. Acuerdo 1 de 2007. No. 46.516 de 19 de enero de 2007. [en línea] Disponible en: http:// www.cntv.org.co/cntv_bop/basedoc/acuerdo/ cntv/2007/acuerdo_cntv_0001_2007.html (Consulta: 22 de julio de 2010.

5. Herrera, S. (2005). Tipología de los observatorios de medios en Latinoamérica. Revista Palabra Clave (13).

6. Ortiz, G.; \& López, F. (2002). La observación de medios en la construcción de una comunicación sostenible para Colombia. Revista Palabra Clave (007).

7. Personería de Bogotá. Ley 850 del 2003 y el Acuerdo 142 de 2005 por la cual se reglamentan las veedurías ciudadanas. [en línea] Disponible en: http://www. personeriabogota.gov.co/?idcategoria $=1255$ (Consulta: 22 de julio de 2010).

8. Torrico, Erick. 2009. Por unos medios de calidad. [en línea] Disponible en: http://www.eldeber.com.bo// rblog/onadem/2009/05/por_unos_medios_de_ calidad.html (Consulta: 14 de abril de 2010).

9. Zuluaga, Jimena (2007). Observatorios de medios. Nuevos actores de la esfera pública. Tesis de Maestría en Comunicación. Pontificia Universidad Javeriana. Bogotá (Colombia).

\section{Entrevistas}

10. Alejandro Rodríguez. Docente Universidad Central. Entrevista personal: 26 de marzo de 2010.

11. Andrés Felipe Giraldo Dávila. Coordinador Observatorio de Medios Facultad de Comunicación Universidad de Medellín. Entrevista por correo electrónico: 14 de marzo de 2010.

12. Carla Ricci. Coordinación Ejecutiva Proyecto Ascun/ CNTV. Entrevista personal: 7 de abril de 2010.

13. Diego Alonso Sánchez. Director del Programa de Comunicación - Periodismo Universidad Lasallista, Caldas Antioquia. Entrevista por correo electrónico: 27 de abril de 2010.

14. Félix Lozano Cárdenas. Docente Programa de Comunicación Social. Coordinador Observatorio de Medios de Comunicación Regional. Universidad Francisco de Paula Santander, Cúcuta. Entrevista por correo electrónico: 22 de marzo de 2010.
15. Jorge A. Gutiérrez. Docente e investigador de la Facultad de Ciencias Sociales y Humanas de la Universidad Autónoma del Caribe. Entrevista por correo electrónico: 13 de abril de 2010.

16. Juan Camilo Hernández. Docente investigador del Observatorio de Medios de la Universidad de la Sábana. Entrevista personal: 18 de marzo de 2010.

17. Julián Burgos. Docente y Coordinador del Observatorio de Medios y Opinión Pública de la Universidad de Manizales. Entrevista por correo electrónico: 23 de marzo de 2010.

18. Mamfry GómezDita.DocenteFacultadComunicación y Artes Audiovisuales de la Universidad Autónoma de Bucaramanga. Entrevista por correo electrónico: 5 de abril de 2010.

19. Mari Luz Vallejo. Docente y coordinadora del Observatorio de Medios de la Pontificia Universidad Javeriana. Entrevista personal: 6 de abril de 2010.

20. Martha Milena Barrios. Docente y Directora de Observatorio de Medios y Opinión Pública de la Universidad del Norte. Entrevista por correo electrónico: 25 de marzo de 2010.

21. Pedro Pablo Aguilera, Director de Departamento de Humanidades y Coordinador del Observatorio de Medios de la Universidad Santiago de Cali. Entrevista por correo electrónico: 19 de abril de 2010. 